\title{
In Situ Investigation of the Silicon Carbide Particles Sintering
}

\author{
Yu Niu, ${ }^{1}$ Feng Xu, ${ }^{1}$ Xiaofang Hu, ${ }^{1}$ Jianhua Zhao, ${ }^{1}$ Hong Miao, ${ }^{1}$ Xiaoping Wu, ${ }^{1}$ \\ and Zhong Zhang ${ }^{2}$
}

${ }^{1}$ Key Laboratory of Mechanical Behavior and Design of Materials, Chinese Academy Sciences, University of Science and Technology of China, Hefei 230026, China

${ }^{2}$ National Center for Nanoscience and Technology of China, Beijing 100190, China

Correspondence should be addressed to Feng Xu, xufeng3@ustc.edu.cn

Received 31 May 2010; Accepted 31 July 2010

Academic Editor: Jaetae Seo

Copyright (C) 2011 Yu Niu et al. This is an open access article distributed under the Creative Commons Attribution License, which permits unrestricted use, distribution, and reproduction in any medium, provided the original work is properly cited.

\begin{abstract}
A real-time observation of the microstructure evolution of irregularly shaped silicon carbide powders during solid state sintering is realized by using synchrotron radiation computerized topography (SR-CT) technique. The process of sintering neck growth and material migration during sintering are clearly distinguished from 2D and 3D reconstructed images. The sintering neck size of the sample is presented for quantitative analysis of the sintering kinetics during solid state sintering. The neck size-time curve is obtained. Compared with traditional sintering theories, the neck growth exponent (7.87) obtained by SR-CT experiment is larger than that of the two-sphere model. Such condition is discussed and shown in terms of sintering neck growth, in which the sintering process slows down when the particle shape is irregular rather than spherical.
\end{abstract}

\section{Introduction}

Silicon carbide ceramic was the earliest forms of artificial abrasives because of its high mechanical strength. Stable chemical properties, high thermal conductivity, thermal expansion coefficient, and other fine performance characteristics have allowed silicon carbide to become widely used in various fields such as coating materials, refractory, and metallurgy [1-3]. Solid state sintering is the key process of preparation of silicon carbide ceramics. Researching the internal microstructure evolution of the sample during the sintering process is important because the microstructure of the material plays a decisive role in macroscopic properties [4-6]. This topic has been extensively investigated since the 1950s [7-9]. Studies on the microstructure improvement of the ceramic materials are meaningful for increasing the production process and improving material properties. However, in the study of solid state sintering, the experimental study of microstructure evolution result has not yet attained a satisfactory level in comparison to theoretical work and numerical simulation. This situation may be attributed to the difficulty of observing the internal microstructure morphology of the sample during the heating process of the solid state sintering in real time. Generally, after solid state sintering, the sample is observed postmortem by scanning electronic microscopy (SEM). Although SEM can provide high resolution photos, this experimental method has eminent shortcomings: (1) cutting and polishing of the samples are bound to damage the original structure; (2) interruption of sintering process and dropping of temperature bring unpredictable impact to the microstructure.

Using SR-CT technique, in situ observation of material under action of outside field (e.g., pressure field, temperature field, etc.) becomes possible $[10,11]$. For the limitation of experimental skills, only a few scholars have conducted research on solid state sintering process by this method. Vagnon et al. did research on stress varying during solid state sintering process of steel powder compacts by SR-CT [12]. Through this technology, Olmos et al. researched the solid state sintering process of a mixture of metallic powder [13]. Grain evolution of boron carbide powders is observed and discussed in this paper during sintering using SR-CT technique [14].

In this paper, the microstructure evolution of silicon carbide powder is investigated in situ by SR-CT technique during the solid sintering process. Using filter back projection 
arithmetic and digital image processing method, 2D sections and $3 \mathrm{D}$ reconstructions of the internal microstructure of samples at different sintering times are carried out. The features of the typical morphology evolution of solid sintering are observed. The size of the sintering neck in each crosssection image is calculated by using watershed algorithm. Neck size-time curve is obtained and compared with existing theories. The linear relationship between neck size logarithm and time logarithm during isothermal sintering is obtained and shown as the neck size-time double logarithm curve, as described in traditional sintering theories. Sintering neck growth exponent is obtained as $n=7.87$, which is a little bigger than the conclusion of two-sphere model, and the reason is qualitatively analyzed.

\section{Experiment}

2.1. Technical Principle. SR-CT technique is a nondestructive testing method by which the specimen passed through by synchrotron radiation $\mathrm{X}$-ray is placed in a rotation, and the projection images of the specimens are received by an $\mathrm{X}$ ray charge-coupled device (CCD). One projection image is collected each time a specimen turns for an angle. After obtaining a set of projection data, reconstruction algorithm is used to obtain the internal microstructure of the sectional images. The 3D images of the microstructure can be obtained from a series of sectional images. Reconstruction algorithms applied in SR-CT technique are mainly filtered by back projection and iterative algorithms. Taking the limited time into account, filtered back projection algorithm is employed in this paper.

2.2. Equipment and Experimental Procedure. Silicon carbide powder for this experiment is chemically pure (99.9\%). The average diameter is approximately $125 \mu \mathrm{m}$. The experiment was carried out on the $4 \mathrm{~W} 1 \mathrm{~A}$ beam line at the Beijing Synchrotron Radiation Facility (BSRF), Beijing, China. A schematic of such SR-CT projection imaging facility is given in Figure 1. A wide collimated synchrotron radiation $\mathrm{X}$ ray (up to $14 \mathrm{~mm} \times 10 \mathrm{~mm}$ ) with energy range from 3 to $24 \mathrm{keV}$ is available. An X-ray with $24 \mathrm{keV}$ selected by silicon single-crystal monochromatic was used in this test. The samples were heated in a sintering furnace specifically designed for SR-CT. This furnace has range of a room temperature to $1600^{\circ} \mathrm{C}$, an even temperature region of $2 \mathrm{~cm}^{3}$, and the highest heating rate of $300^{\circ} \mathrm{C} / \mathrm{h}$. There is a corundum cylinder connecting with a rotation device in the furnace. The MRS102 rotation device, with angle resolution of $0.00125^{\circ}$ and repeatable positioning accuracy of $0.005^{\circ}$, was provided by the Beijing Optical Instrument Factory. The samples were introduced on top of the corundum cylinder. The synchrotron radiation $\mathrm{X}$-ray passed through samples and reached an X-ray CCD detector, which recorded the intensity message of X-ray. The CCD including a $1300 \times$ 1030 pixels chip with a unit pixel of $10.9 \times 10.9$ um $^{2}$ offered an 8-bit dynamic range. At different sintering times, the sample was imaged at different projection angles (in the range of $0-180^{\circ}$ ). Typically, 180 shadow images of the sample

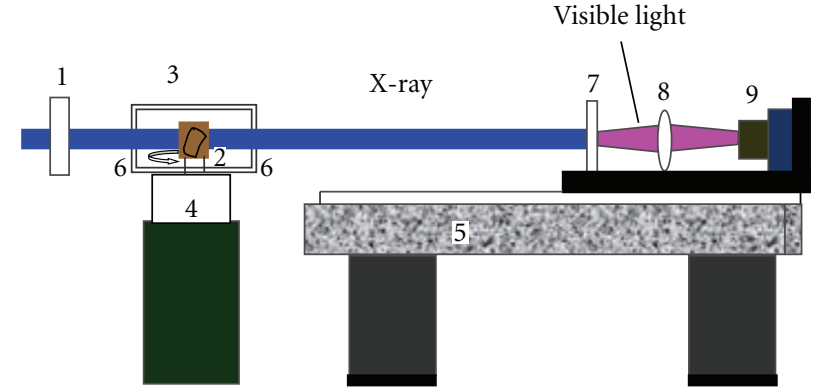

FIGURE 1: Schematic diagram of SR-CT projection imaging facility 1. X-ray source 2. Sample 3. Sintering furnace 4. Rotation device 5. Antivibration platform 6. Holes 7. Fluorescent target 8. Optical 9.CCD.

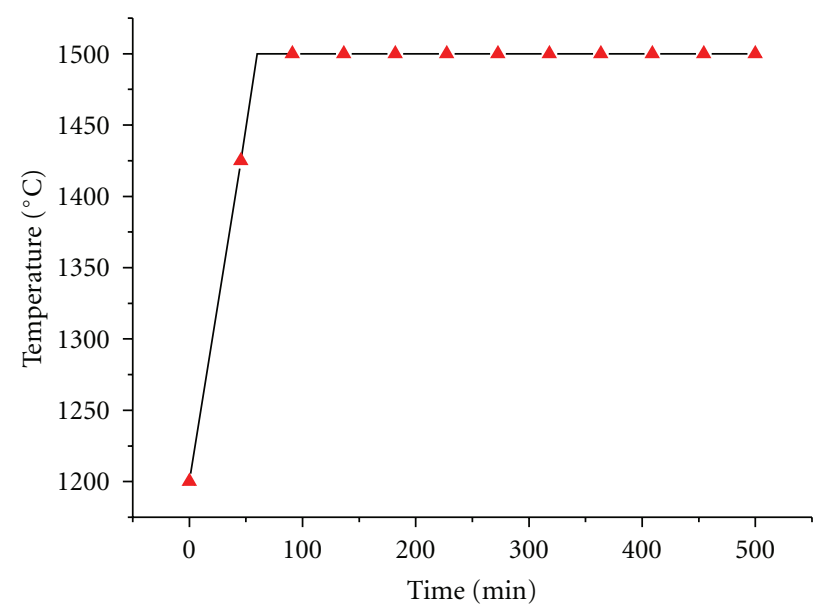

Figure 2: Heating process and record point.

were acquired. These images were then processed by the filtered back projection algorithm $[15,16]$.

Temperature is an important parameter in sintering. In order to compare with the conclusion of traditional theory and experiment, an isothermal sintering process was designed for eliminating the influence of temperature change.

In this experiment, the sintering temperature reached $1500^{\circ} \mathrm{C}$ with the highest heating rate. The temperature was held at $1500^{\circ} \mathrm{C}$. Temperature-time curve is shown in Figure 2.

\section{Results}

A 2D cross-correlation algorithm was used to detect crosssection images at different sintering times. The reconstructed images of the same cross-section at different times are shown in Figure 3. Grayscale range is from 0 to 255; the closer to 255 , the higher the relative density, which means white represents particles and black represents holes.

Vertical section and $3 \mathrm{D}$ reconstructed images can also be obtained by treating the cross-section images with 


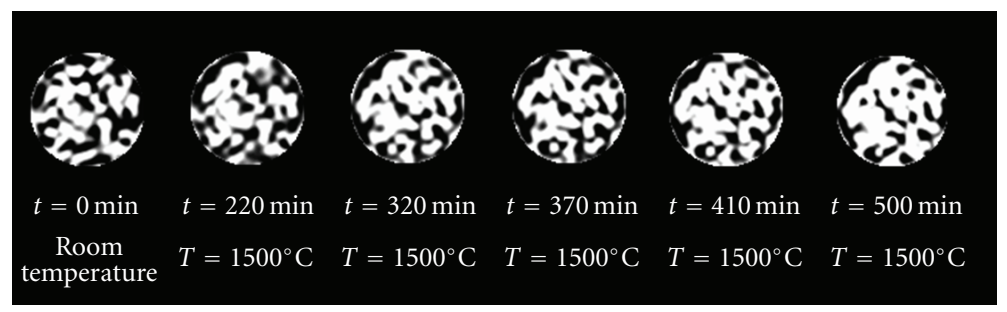

FIGURE 3: Reconstructed images of the same cross-section of the sample at different sintering periods.

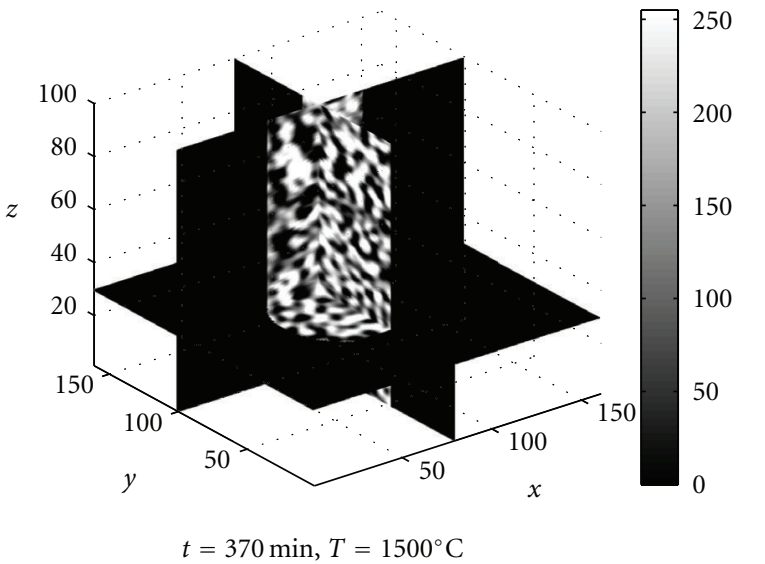

(a)

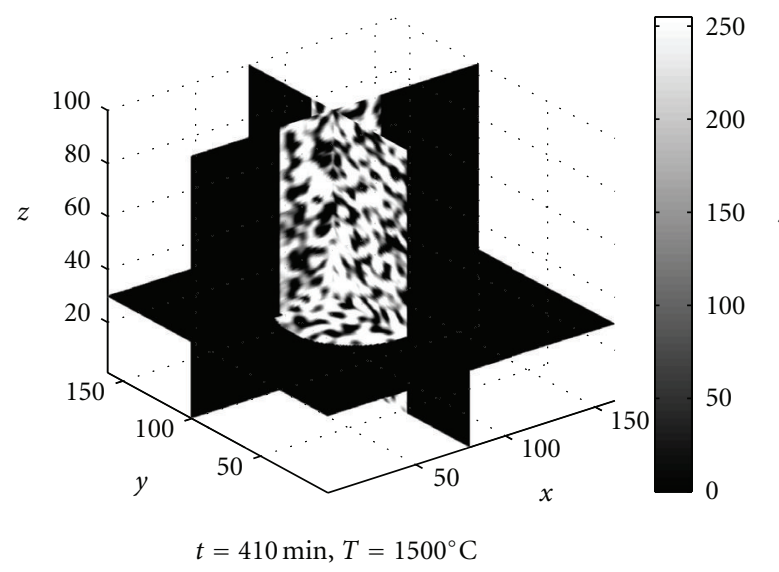

(c)

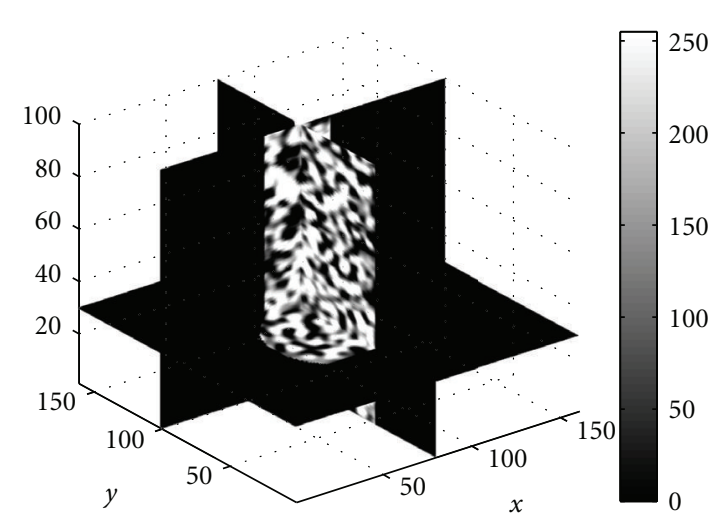

$t=370 \min , T=1500^{\circ} \mathrm{C}$

(b)

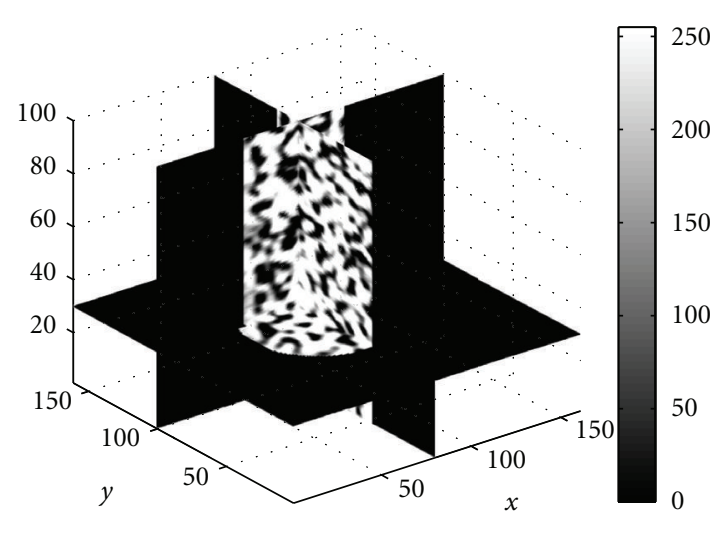

$t=500 \min , T=1500^{\circ} \mathrm{C}$

(d)

Figure 4: Sectional view in different directions.

digital image processing method. For quick identification, a Cartesian coordinate system is considered and shown in Figure 4. The plane $X O Y$ is defined as the initial cross-section of the reconstructed part of the sample.

By applying 3D reconstruction algorithm, a series of the cross-section images was assembled to obtain a 3D image and the sections in any position of the sample, as shown in Figure 4.

Figure 5 shows the 3D reconstructed images of the sample. The 3D morphology evolution of the sample by increasing the sintering time can be clearly observed from Figure 5.

\section{Discussion}

Various sintering phenomena could be observed clearly from the reconstructed images (Figures 3-5), such as the growth of sintering neck, the interconnected pores becoming isolated and spherical, the sample becoming dense, and so forth.

At different sintering times, 100 consecutive crosssections at the same ordinate (from $z=1$ to $z=100$ ) of the sample were selected. Sintering neck in each section was extracted. First, the watershed method was applied for segmentation of the section image (Figure 6(b)). Next, the connection between the different particles was considered 


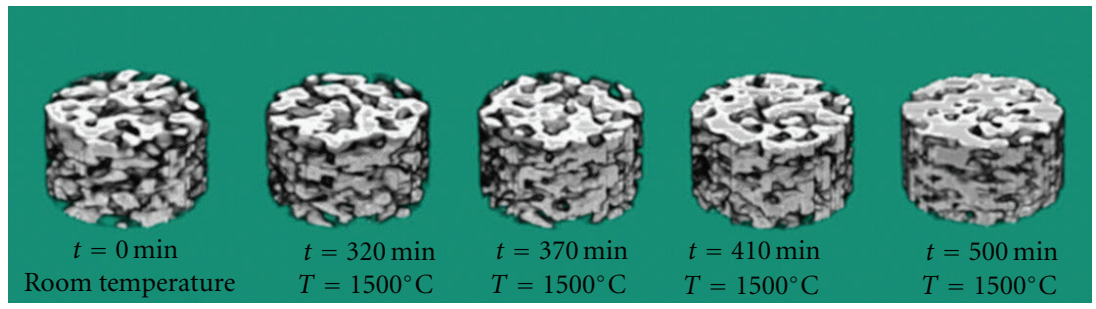

FIGURE 5: Three-dimensional reconstructed images of the sample at different sintering periods.

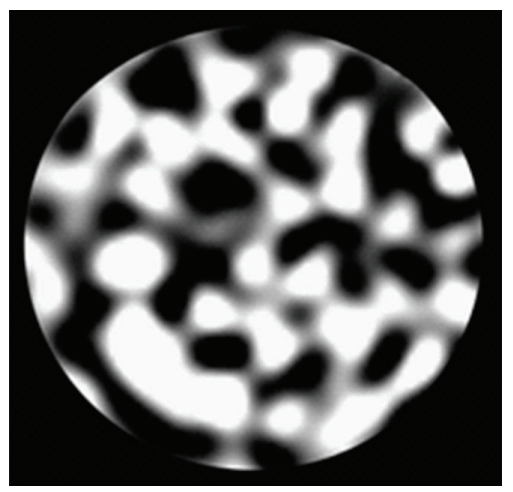

(a)

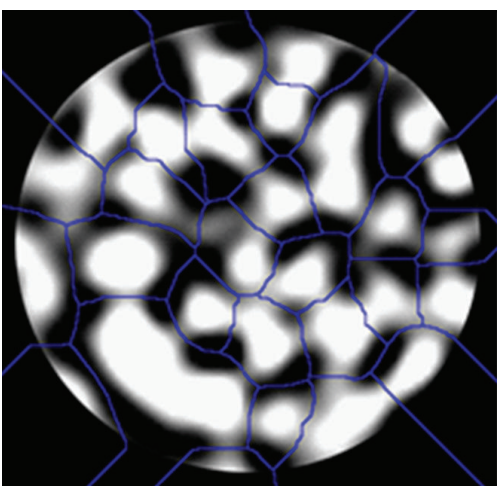

(b)

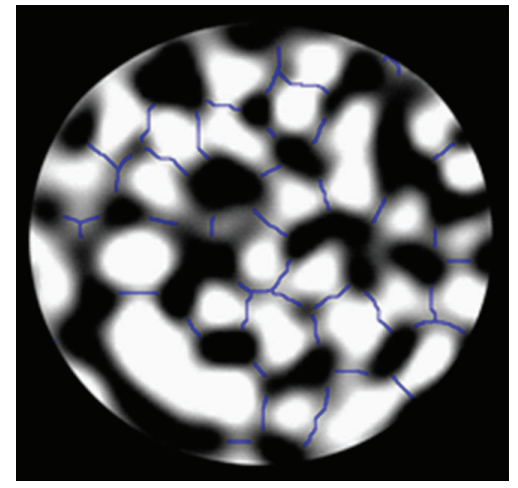

(c)

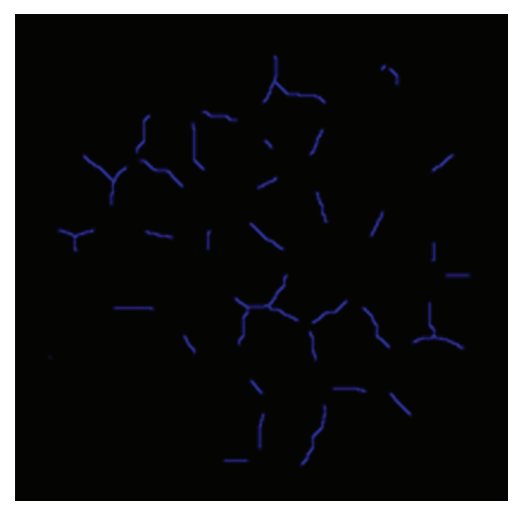

(d)

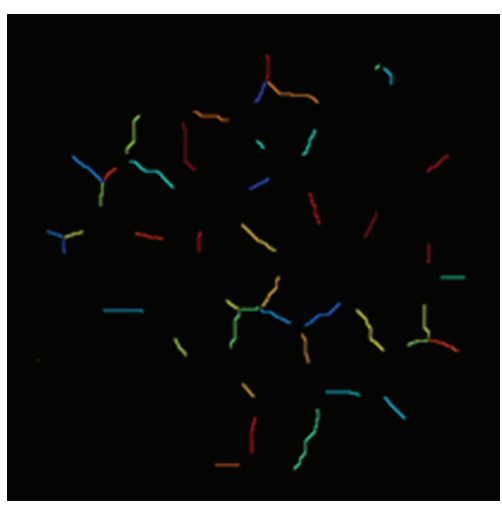

(e)

Figure 6: The process of extracting the sintering neck.

as a sintering neck (Figure 6(c)). Sintering necks were extracted (Figure 6(d)). Finally, different sintering necks were distinguished by employing texture segmentation and watershed [17] (Figure 6(e)).

In order to verify the uniformity of the statistical parameters in spatial location, the distribution of sintering neck size in each cross-section was summarized, as shown in Figure 7. Distribution suggests that once the time is determined, the size of sintering neck would not change with the spatial location in the direction of $\mathrm{z}$-axis. Therefore, the neck growth with the average sizes at different moments during the sintering process (Figure 8) was analyzed.

Neck growth has great influence on shrinkage during solid state sintering and plays an important role in determining the main diffusion mechanism and calculating the diffusion coefficient of the material [18]. Therefore, many scholars have researched sintering neck growth under various mechanisms in theory. Various forms of neck growth equation have been obtained [19].

The dynamics of stable neck-growth as summarized by Kucsynski is shown in the formula below:

$$
\left(\frac{x}{a}\right)^{n}=\frac{F(T)}{a^{m}} t
$$

In our observation of the sintering process, grain growth was not obvious. We believe that when the degree of densification is low, the grain size changes only slightly. In other words, the average grain size is a constant. Moreover, Figure 9 shows that a good linear relationship of $\ln (x)$ $\ln (t)$ is consistent with the conclusions of Kucsynski. The reciprocal of the slope of the straight line represents the sintering neck growth exponent $n$. Thus, according to our 


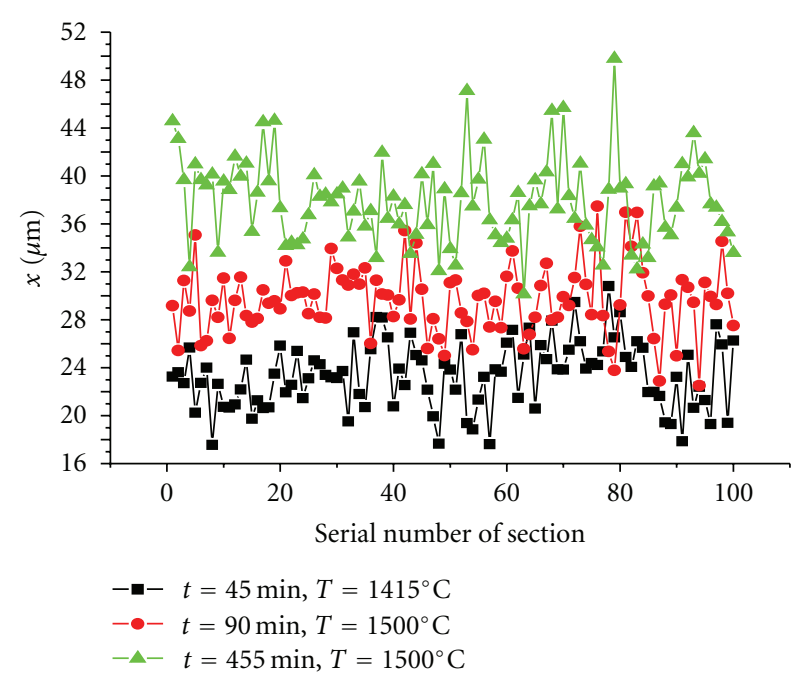

Figure 7: The distribution of sintering neck size in different sections.

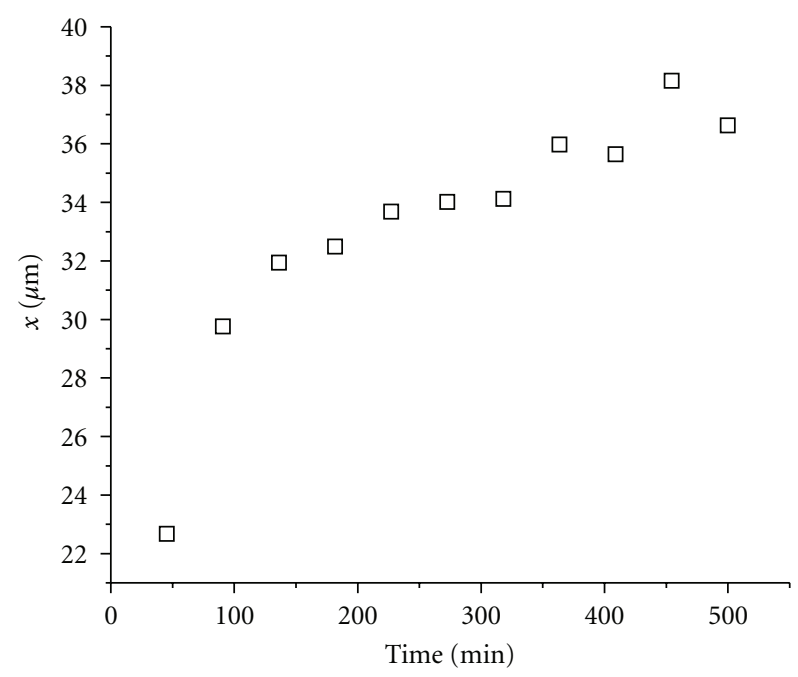

FIgURE 8: Mean neck size in different sintering times.

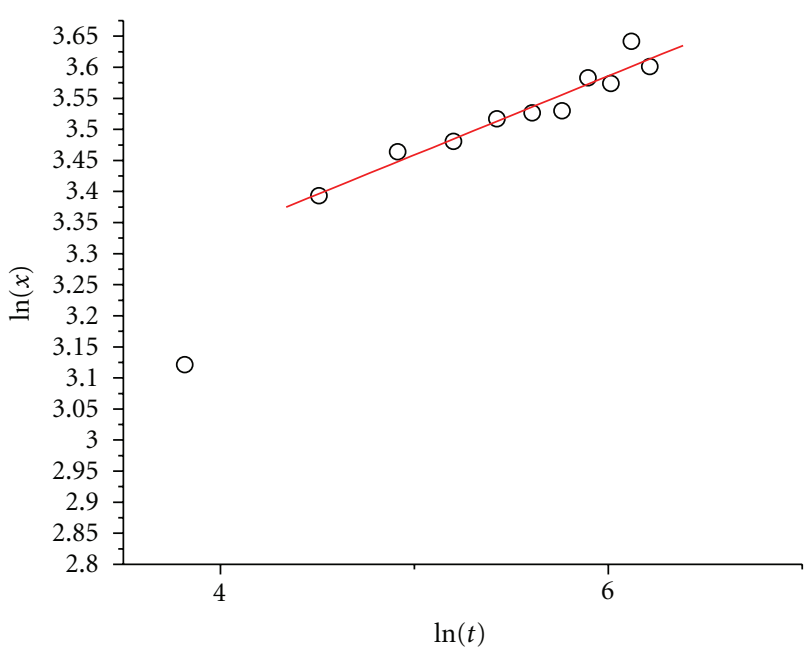

FIGURE 9: Double logarithm curve of mean neck size and time. experimental results, if $\ln (x)-\ln (t)$ slope of the line fitted by least squares is 0.127 , then $n=7.87$. This value is larger than the result deduced by the two-sphere model $(n=2-7)$ [20]. In other words, the neck growth rate of irregularly shaped particles is smaller. Such condition can be attributed to that the shape of the particle has important influence on sintering neck growth rate. Takayasu and others pointed out that the sintering process of polyhedral particles is slower than that of the spherical particles [21]. The shape of particles determines the initial contact between particles and the size of dihedral angle, and all of these are important factors for sintering neck growth. In addition, compared to spherical particles, the more complex geometry of particles is, the greater the specific surface area is. Thus, the distance of surface diffusion is increased, and the effect of diffusion is reduced. During our experiments, the powders were irregularly shaped silicon carbide particles used in common industrial production. Inevitably, such shape displays disadvantages in neck growth, explaining why the sintering of spherical particles is better than the same process applied in irregularly shaped particles taking neck growth in consideration. However, from the view of phenomenology, the law of $(x / a)^{n}=$ $K \cdot t$ still exists during the sintering of irregular-shaped particles.

In addition, the value of $n$ was close to 7 . According to exponential criterion, such relationship is presented between different values of $n$ and main mechanisms, such that $n=$ 5 indicates bulk diffusion taking the most part, $n=6$ indicates grain boundary diffusion, and $n=7$ indicates surface diffusion. In our experiment, surface diffusion played a leading role during sintering. The effect of surface diffusion on sintering nonmetallic powders $\left(\mathrm{MgO}, \mathrm{Al}_{2} \mathrm{O}_{3}\right)$ was quantitatively estimated in 1989 [22], and it was concluded that the shrinkage between two particles is reduced 45 orders of magnitude for the participation of surface diffusion. Furthermore, it is pointed out that such a negative impact is more serious on ceramic powders with covalent bonds such as $\mathrm{Si} \mathrm{SiC} \mathrm{BN}$ and AlN. In our experiment, the microstructure of the sample changed dramatically; however, the densification failed to reach high degrees. Integrating previous conclusions, the surface diffusion is believed to play a significant role in this phenomenon.

\section{Conclusion}

The microstructure evolution of irregular-shaped silicon carbide powder was observed in situ with the SR-CT technique during solid state sintering process.

(1) A series of 2D and 3D reconstructed images of silicon carbide powder during sintering process was obtained. The microstructure evolution of silicon carbide powder and many sintering phenomena during three sintering stages were clearly observed.

(2) Neck growth between irregularly shaped ceramic powders during sintering process was calculated. Neck growth exponent was identified as $n=7.87$, and compared with the conclusion of the two-sphere model. 
(3) By comprehending different sintering mechanisms, a qualitative analysis of the reason why the neck growth exponent is bigger than the result of traditional theory has been conducted, explaining why the irregular-shaped particles reduce the rate of the sintering when compared with the spherical ones taking sintering neck growth into consideration. Meanwhile, the importance of the original shape of particles to neck growth has been pointed out experimentally.

\section{Foundation Item}

Projects nos. 10902108, 10732080, and 10872190 supported by the National Nature Science Foundation of China, Project supported by the National Basic Research Program of China (973 Program, Grant no. 2007CB936800), and Project supported by BSRF Foundation.

\section{Acknowledgments}

This paper was supported by the National Nature Science Foundation of China under Contract nos. 10902108, 10732080, and 10872190, the National Basic Research Program of China (973 Program) no. 2007CB936800, and BSRF Foundation. The authors warmly thank Zhu Peiping Huang Wanxia and Yuan Qingxi for their help in preparing the experiments, as well as Qu Hongyan, Li Yongcun for fruitful discussions and assistance in conducting the experiments.

\section{References}

[1] V. Luchinin and Y. Tairov, "Silicon carbide, a diamond-like material with controllable nanostructure-depending properties," Nanoindustry, vol. 1, no. 1, pp. 36-40, 2010.

[2] R. Yilmaz, "Thermal diffusivity measurement of SiC fibre reinforced BMAS glass ceramic composites exposed mechanical damage," Journal of the European Ceramic Society, vol. 27, no. 2-3, pp. 1223-1228, 2007.

[3] K. Y. Cheong and Z. Lockman, "Growth mechanism of cubicsilicon carbide nanowires," Journal of Nanomaterials, vol. 2009, Article ID 572865, 5 pages, 2009.

[4] J. L. Shi, "Solid state sintering (I)-pore microstructural model and thermodynamic stability, densification equation," Journal of the Chinese Ceramic Society, vol. 25, no. 5, pp. 499513, 1997.

[5] J. L. Shi, "Solid state sintering (II)—relation between coarsening and densification and mass transport path," Journal of the Chinese Ceramic Society, vol. 25, no. 6, pp. 657-668, 1997.

[6] J. L. Shi, "Solid state sintering (III)—experimental study on grain and pore growth, and densification of superfine zirconia powder compacts," Journal of the Chinese Ceramic Society, vol. 26, no. 1, pp. 1-13, 1998.

[7] R. L. Coble, "Initial sintering of alumina and hematite," Journal of American Ceramic Society, vol. 41, no. 2, pp. 55-62, 1958.

[8] R. L. Coble, "Sintering crystalline solids. I. intermediate and final state diffusion models," Journal of Applied Physics, vol. 32, no. 5, pp. 787-792, 1961.
[9] R. L. Coble, "Sintering crystalline solids. II. experimental test of diffusion models in powder compacts," Journal of Applied Physics, vol. 32, no. 5, pp. 793-799, 1961.

[10] M. Di Michiel, J. M. Merino, D. Fernandez-Carreiras et al., "Fast microtomography using high energy synchrotron radiation," Review of Scientific Instruments, vol. 76, no. 4, Article ID 043702, 7 pages, 2005.

[11] X. Li, X. Hu, Y. Hu, and Y. Kan, "Synchrotron radiation tomography for reconstruction of layer structures and internal defects of composite materials," Chinese Journal of Lasers B, vol. 8, no. 6, pp. 503-508, 1999.

[12] A. Vagnon, O. Lame, D. Bouvard, M. Di Michiel, D. Bellet, and G. Kapelski, "Deformation of steel powder compacts during sintering: correlation between macroscopic measurement and in situ microtomography analysis," Acta Materialia, vol. 54, no. 2, pp. 513-522, 2006.

[13] L. Olmos, T. Takahashi, D. Bouvard et al., "Analysing the sintering of heterogeneous powder structures by in situ microtomography," Philosophical Magazine, vol. 89, no. 32, pp. 2949-2965, 2009.

[14] F. Xu, X. F. Hu, Y. Niu, J. H. Zhao, and Q. X. Yuan, "In situ observation of grain evolution in ceramic sintering by SR-CT technique," Transactions of Nonferrous Metals Society of China, vol. 19, no. 3, pp. S684-S688, 2009.

[15] P. Grunert, J. Mäurer, and W. Müller-Forell, "Accuracy of stereotactic coordinate transformation using a localisation frame and computed tomographic imaging-part I: influence of the mathematical and physical properties of the CT on the image of the rods of the localisation frame and the determination of their centres," Neurosurgical Review, vol. 22, no. 4, pp. 173-187, 1999.

[16] T. G. Zhuang, "The theory and arithmetic of computedtomography," in CT Reconstruction Algorithm, pp. 30-60, Shanghai Jiao Tong University Press, Shanghai, China, 1992.

[17] R. C. Gonzalez, R. E. Woods, and S. L. Eddins, "Digital image processing using Matlab," in Digital Image Processing, M. D. Yan, Ed., pp. 315-317, Publishing House of Electronics Industry, Beijing, China, 2005.

[18] D. L. Johnson, "New method of obtaining volume, grainboundary, and surface diffusion coefficients from sintering data," Journal of Applied Physics, vol. 40, no. 1, pp. 192-200, 1969.

[19] S. L. Kang, "Sintering-densification, grain growth, and microstructure," in Sintering Theory, J. Hill, Ed., pp. 51-52, Elsevier, London, UK, 2005.

[20] J. S. Guo, "Powder sintering theory," in Sintering Theory, F. Xiao, Ed., pp. 41-43, Metallurgy Industry Press, Beijing, China, 1998.

[21] T. Ikegami, "Early-stage sintering in a powder compact of polyhedral particles: I. Models," Ceramics International, vol. 25, no. 5, pp. 415-424, 1999.

[22] R. Pampuch and J. Lis, "Specific aspects of sintering of micropowders," Solid State Phenomena, vol. 8-9, pp. 83-93, 1990. 

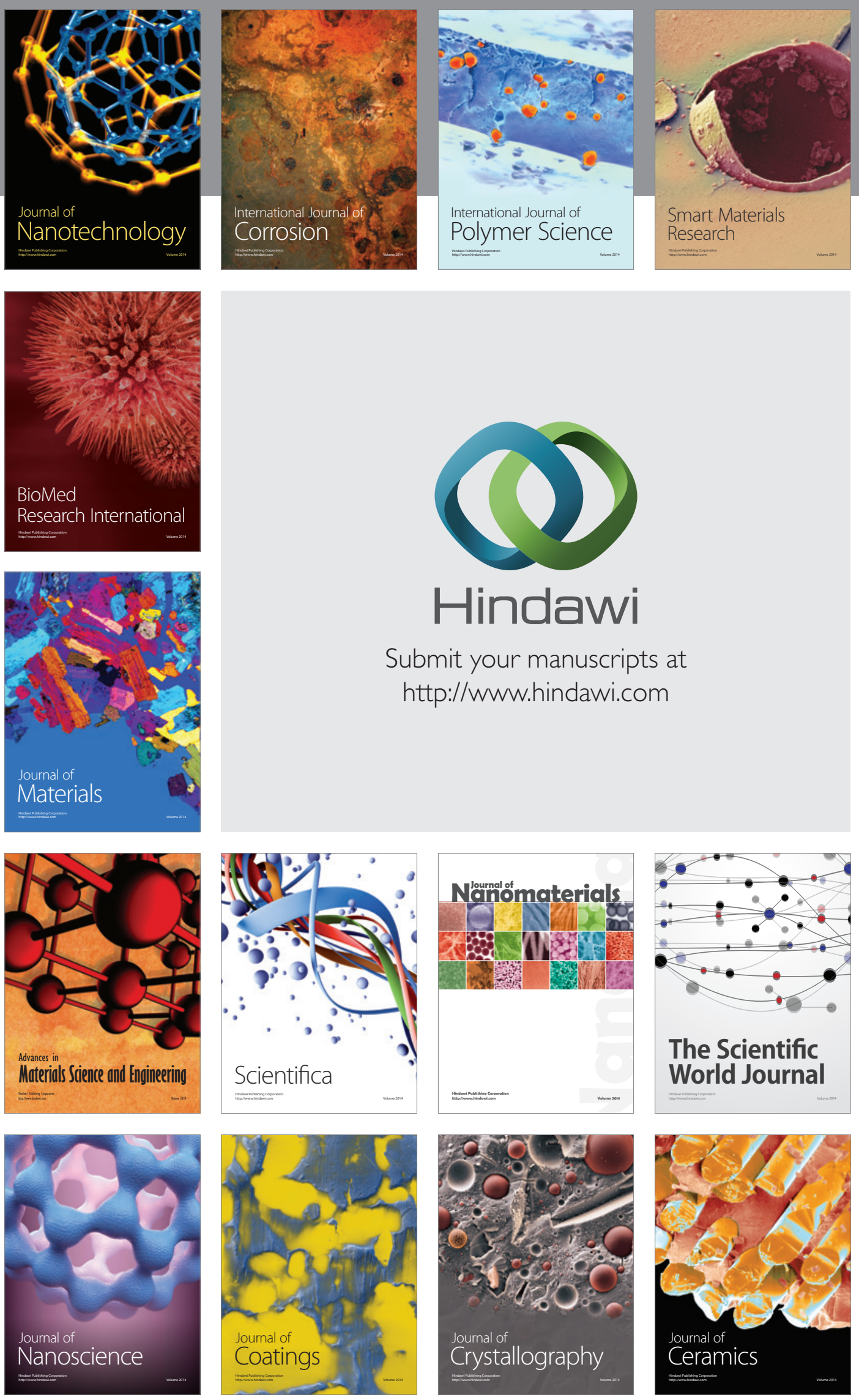

The Scientific World Journal

Submit your manuscripts at

http://www.hindawi.com

\section{World Journal}

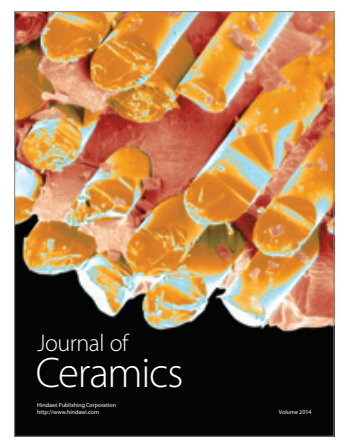

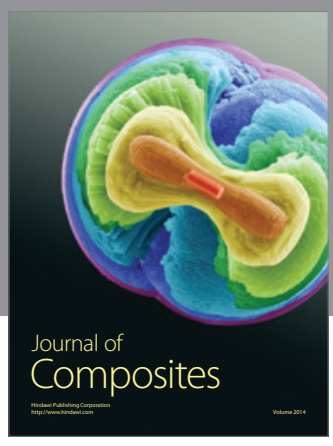
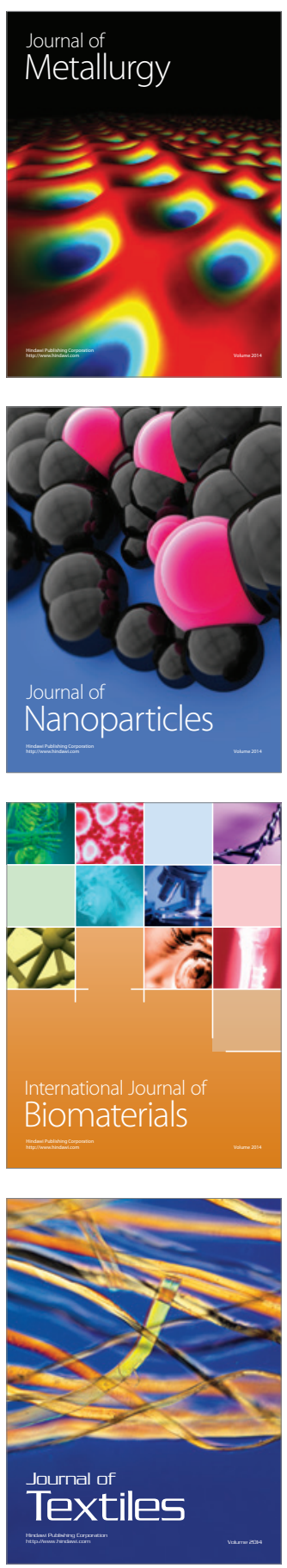